\title{
MODIFICATION OF DELIVERY PRACTICE IN RAJBANSHI MOTHERS OF NEPAL
}

\author{
Nawaraj Subba, Shishir Subba
}

\begin{abstract}
Introduction: This is a cross-sectional study with the objective of identifying modification in delivery practice in Rajbanshi mothers of Nepal.

Methodology: Both qualitative and quantitative tools were used. Semi-structured questionnaires covering 375 samples of its resident districts Morang, Jhapa and Sunsari districts and check lists for in-depth interview were used in the study.

Results: People were adopting both traditional and modern care practices concurrently. Among 375 households; 40\% adopted local clinic/ hospital/ traditional healer concurrently. Similarly $31.20 \%$ adopted local clinic/ traditional healer/ hospital, 10.67\% adopted hospital/traditional healer. There were $11.47 \%$ (urban $0.54 \%$ and rural $10.93 \%$ ) respondents were having traditional care system as a first choice. During first delivery among 375 mothers $265(70.67 \%)$ had traditional home delivery and $110(29.33 \%)$ had hospital delivery. During last delivery, this was $115(30.67 \%)$ in traditional home delivery and $260(69.33 \%)$ in hospital delivery. Therefore trend of hospital delivery was increasing whereas trend of traditional home delivery was decreasing. It was statistically highly significant $(\mathrm{p}=<0.0001)$. There was also remarkable increased in using trained Health Worker/Nurse/Doctor at hospitals is $66.4 \%$ during last delivery which was only $6.13 \%$ during first delivery. It is statistically highly significant $(p=<.0001)$.
\end{abstract}

Conclusion: Trend of hospital delivery was increasing (from 30.67\% to $69.33 \%$ ) and trend of home delivery was decreasing (from $69.33 \%$ to $29.23 \%$ ) in between first and last child delivery. There was remarkable increased in using trained HW/Nurse/Doctor at hospitals is $66.4 \%$ during last delivery which was only $6.13 \%$ during first delivery. Traditional care was more practiced in rural than in urban population.

Keywords: Traditional home delivery, Modern hospital delivery, Rajbansi, Nepal

\section{Introduction}

The word Rajbanshi means "dynasty of king". Rajbanshi were dwelt and over populated in the Koc-Bod area of upper Tibetan plateau was known as Koch or Koches. These people came down to southern region and also Bramhaputra river valley sometime between 7000 to 5000 B.C. and so physical changes through various doors i.e. hilly paths or passages. When
Koches were over populated in the Koc-Bod areas one branch of the common stock achieved prominence around the Kochi (Koshi or Kosi) river banks and in areas between lower Nepal and north Bihar (1).

Rajbanshi themselves considered as Kchhetriya of Hindu caste system. Anthropologists have opined that they are the kiths and kin of the peripheral Koch people of the adjacent states of West Bengal and Asom 
(Assam) in India. As described in the blogspot of Social Organization of Rajbanshi Aborigines soranepal, they are having Mongoloid features - they consider themselves as a branch of the Kirants. They have a liftedT bone over their throat a little higher than the average height. The structure of their eyes and forehead, etc is like those of a mix of AryanMongloid, Austric, Negrito, Dravidian. They wear clothes conforming to climate and weather. Their physical charecteristics are similar with local indigienous people like Tharu, Meche, Dhimal, Nuniya and Batar.

Referering to Ridge(2) has mentioned in article that there are different kinds of Rajbanshis such as Koch Rajbanshi, Poundra Rajbanshi, Mech Rajbanshi, Newar Rajbanshi, and Khataha Rajbanshi in Nepal. There are mainly more than four types of Rajbanshi found in Nepal. Khotaha Rajbanshi- They are Maithil language speaking. They have poor economic or social condition. They even take alcohol and eat pork, chicken, rat and a kind of snail ghongi. They believed that during Ramayan era when Parshu Ram started genocide against Kchhetryas some run away from their place to hide northern part which is now territory of Nepal and they have been settled here since Ramayan era. According to Shrestha(3) their castes are called- Teli, Baniya, Gwar, Kahal, Khatwe, Kipat, Dhanuk, Nuniya, Amat, Kalawar, Kamat, Koiry, Sharma, Pandit, Ganesh, Chuhan, Chanda and Mana Chanda. They are habited in Biratnagar city covering from east of Sindhiya river and have marital linkage with Rajbanshi of Purniya in Bihar. Rajput Rajbanshi- They believed that they are proceeder of Rajbanshi dynasty as pure Kchhetriya. Their habitat is located west of Morang to Saptari. According to Shrestha (3) their castes are called as- Chandel, Chauhan, Kachwaha, Parihar, Ponwar, Rathaur, Bhisaudiya, Solankhi, Tinwar, Yadav, Jaath, Gujer etc. Newar Rajbanshi- during Malla dynasty in Kathmandu Valley Malla king married Koch princess. So, it is believed that since Malla dynasty or before Newar Rajbanshi or Koch are living in Kathmandu as Newar Rajbanshi. Newar Rajbanshi has Newar culture and language in Kathmandu valley. Bangali Rajbanshi- is also known as Petani Rajbanshi since they wear dress called Petani by women Rajbanshi. Their tradition and culture are similar with Rajbanshi of West Bengal and Assam. These Rajbanshi in Nepal are living before unification of Nepal. Apart from these Rajbanshi there are Bongaha, Hadi, Paliya, Majhi and Gosai Rajbanshi found in Nepal.

In Nepal there are 59 indigenous people dwelling. Rajbanshi is one of the indigenous people of their habitat terai region. People speaking the Rajbanshi language was 85,559 in census held in 1991, which increased to 1 , 29,829 in 2001 's census. And according to census 2011 there is 122,214 in numbers speaks Rajbanshi. Rajbanshis are found to have settled in most of the villages in Jhapa and Morang. They are agro-based people but now they are working in different occupation like labour, service and business.

\section{Methods and Tools}

1. Household Survey: general information taken from head of household and detailed questionnaire filled with mother's interview $(n=375)$. 2. Observation: of housing and traditional practices. Tools: 1. Questionnaire (Semi-structured), 2. Check list for Observations. Study Sites: (1) Jhapa and (2) Morang and (3) Sunsari districts. Data entered and analyzed with SPSS-20 software in computer. 


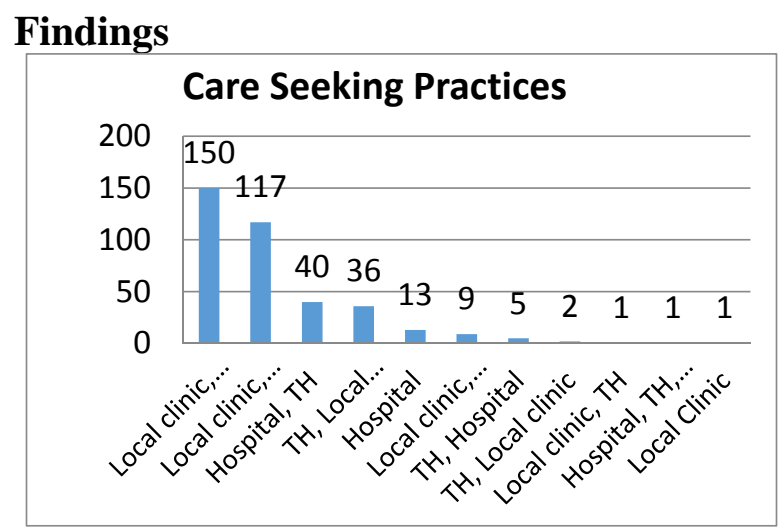

Figure 1 Care Seeking Practices

Figure 1 shows health care practice during sickness. People were practicing multiple care and treatment concurrently. Among 375 sample $40 \%$ (150) of sample preferred local clinic/ hospital/ traditional healer (TH), Which is followed by local clinic/traditional healer/ hospital 31.2\% (117), hospital/ traditional healer $10.67 \%$ (40), traditional healer/ local clinic/hospital 9.6\% (36), hospital only $3.47 \%$ (13), local clinic/hospital 2.4\% (9), traditional healer/hospital $\quad 1.33 \% \quad(5), \quad$ traditional healer/local clinic $0.53 \% \quad(2)$, local clinic/traditional healer $\quad 0.27 \% \quad$ (1), hospital/traditional healer/local clinic $0.27 \%$ (1) and local clinic $0.27 \%$ (1).

Table 1. Change in Delivery Practices

\begin{tabular}{|c|c|c|c|}
\hline \multicolumn{4}{|c|}{ Trend of delivery Practice $(n=375)$} \\
\hline & $\begin{array}{c}\text { 1st } \\
\text { delivery }\end{array}$ & $\begin{array}{c}\text { Last } \\
\text { delivery }\end{array}$ & P-value \\
\hline Home & 265 & 115 & \\
\hline $\begin{array}{l}\text { Hospi } \\
\text { tal }\end{array}$ & 110 & 260 & $\begin{array}{l}<0.0001 \\
\chi^{2}=\end{array}$ \\
\hline Total & 375 & 375 & 118.4264 \\
\hline
\end{tabular}

Table 1 shows that during first delivery among 375 mothers $265(70.67 \%)$ had traditional home delivery and 110 (29.33\%) had hospital delivery. During last delivery, this was decreased by $115(30.67 \%)$ in traditional home delivery and increased by $260(69.33 \%)$ in hospital delivery. Therefore trend of hospital delivery was increasing whereas trend of traditional home delivery was decreasing. Statistically highly significant $(\mathrm{p}=<0.0001)$.

\section{Table 2. Change in Use of Service Providers}

\begin{tabular}{|l|l|l|l|}
\hline \multicolumn{4}{|l|}{ Trend of Service Provider Used $(\mathrm{n}=375)$} \\
\hline $\begin{array}{l}\text { Service } \\
\text { Provider }\end{array}$ & $\begin{array}{l}\text { First } \\
\text { Delivery }\end{array}$ & $\begin{array}{l}\text { Last } \\
\text { Delivery }\end{array}$ & $\begin{array}{l}\text { P- } \\
\text { value }\end{array}$ \\
\cline { 1 - 3 } TBAs & 30 & 7 & \\
\cline { 1 - 1 } & 25 & 5 & $\mathrm{p}=$ \\
\cline { 1 - 2 } TBA/CHW & 254 & 102 & $<.0001$ \\
\cline { 1 - 2 } HW/Nurse & 43 & 12 & $\begin{array}{l}\chi^{2}= \\
297.78\end{array}$ \\
\cline { 1 - 2 } $\begin{array}{l}\text { HW/Nurse/ } \\
\text { Doctor }\end{array}$ & 23 & 249 & \\
\hline
\end{tabular}

Table 2 indicates practice of using service providers. Among 375 mothers regarding using TBAs, $8 \%$ used in first delivery and only $1.87 \%$ in last delivery. Similarly, there is also change in using Health workers at community level was $6.67 \%$ first and $1.33 \%$ at last delivery. Use of TBA/CHW was $67.73 \%$ at first delivery and decreased to $27.2 \%$ at last delivery. Using HW/Nurse was 11.47 at first delivery and $3.2 \%$ at last delivery. But, there was remarkable increased in using HW/Nurse/Doctor at hospitals was $66.4 \%$ at last delivery which was only $6.13 \%$ at first delivery. Therefore there was increasing in practice of modern health system in Rajbanshi community since it is statistically highly significant $(\mathrm{p}=<.0001)$.

\section{Table 3. Traditional practice of Rajbanshi as first choice by urban-rural Setting}

\begin{tabular}{|l|l|l|}
\multicolumn{3}{|c|}{$\begin{array}{c}\text { First choice of Traditional Care by Urban- } \\
\text { Rural }(\mathrm{n}=375)\end{array}$} \\
\hline Setting & Number & Traditional Care \\
\hline Urban & 49 & 2 \\
\hline Rural & 326 & 41 \\
\hline Total & 375 & $43(11.47 \%)$ \\
\hline
\end{tabular}


Table 3 indicates that $11.47 \%$ Rajbanshi had practiced traditional care as first choice. In urban area it is $0.54 \%$ and in rural area it is $10.93 \%$.

A Traditional Birth Attendant (TBA) said: "There is huge difference between today and before. During past days there were traditional healer who used to jharphuk and chanting mantras in water pot with holy basil tulasi leaf and gave pregnant woman to drink and some water sprinkled on the body. After that they used to call TBA and started to massage over stomach. It was risky practice. They didn't have suggested for even antenatal check up. So, maternal death was reported. But today, every woman goes for ANC, take TT, and Iron tabs. They also go to health institutions to take suggestion from health workers. Most of them go to hospital for delivery. Some people still call TBAs for home delivery but when it gets prolonged then I referred to the hospital." (TBA1)

\section{Discussion}

Nepal is a country considered having high maternal mortality rate 229/100,000.(4) and high Child mortality 54/1000 in the region.(5) A variety of traditional care systems exist in Nepal. Ayurveda, Tibetan medicine, indigenous care and faith healing are the major traditional medical systems or folk medicine. Modern or Western allopathic medicine was introduced in the seventeenth century but became dominant from the middle of the 20th century. Multiple and Alternative medical systems are popular in all community in Nepal. This variety is reflected in a tolerant coexistence and co-operation between differing forms of therapeutic practice $(3,6,7)$. A study done before in Katahari and Baijanathpur VDCs of Morang district in same community had noted that Rajbanshi community was adopting modern, self and alternative medications. Modern medication was equally popular in both poor and rich or educated and uneducated.(8) Similarly, a study conducted in Jajarkot also find people were adopting modern, traditional, and natural treatment through the use of herbal medicine and the home/family treatment by food and local herbs.(9)

A cross-sectional study was conducted with 482 Hindu women who were pregnant in Maitha, Uttar Pradesh, India.(10) Maternal health care service use among both upper and lower caste women was very low. Upper caste women were almost three times more likely to use antenatal care. Five times more likely to have a trained birth attendant compared to the lower caste women. Caste was a significant determinant of tetanus toxoid use and trained birth attendant even after adjusting for sociodemographic factors. Various trends of practices are seen in US .(11) The study noted two more that are of interest to us. First, there is the multi-disciplinary approach becoming more and more widely recognized. Dualism describes a situation where one sector of society is developed and "Westernized" and the other sector remains "traditional".(12). Even within a particular culture these two sectors have limited interactions and operate parallel to each other. In addition, the existence of cultural diversity within a particular society could produce the different types of explanations and interpretations.(13)

This study noted that people were both traditional and modern care practices concurrently. Among 375 households; 40\% adopted local clinic/ hospital/traditional healer concurrently. Similarly $31.20 \%$ adopted local clinic/ traditional healer/ hospital, $10.67 \%$ adopted hospital/traditional healer, $9.6 \%$ adopted traditional healer/ local clinic/ hospital, 3.47\% adopted hospital practice, $2.4 \%$ adopted local clinic/hospital, and $1.33 \%$ adopted traditional healer/hospital concurrently. Local clinics were first choice 
$65 \%$ respondents which is modern care and mainly due to availability at local level. 19\% respondents reported the first choice for treatment was hospitals. $11.47 \%$ respondents reported first choice was traditional care system. Study uncovered that $83.50 \%$ respondents went to local clinics when mothers or child get sick, $11.50 \%$ visited traditional healer and $5 \%$ of respondents went to hospitals directly. Therefore, most people were practicing modern care system than traditional when mother and child care.

\section{Changes in traditional practices}

Traditional healers are a part of health care system in Rajbanshi community. They know their limitations and so they do refer to health institutions. Since traditional healers have got trainings from health posts they are aware of modern medications. They treat a case and hold normally for 1-2 days and if there is no sign of progress resulted be refered. Usually they are doing refered people to clinics or hospitals due to social construction of their behavior change. Rajbanshi communities are habited geographically on plain areas so that they have easy access of transportation to get health institutions. Due to efforts of government's public health programs focused especially on mother and child and availability of health workers and volunteers were more attracted with modern health system. Regarding the trend of care seeking practices among 375 mothers $69.33 \%$ had traditional home delivery at first baby and birth was decreased to $30.67 \%$ at last delivery. So, in Rajbanshi the practice of traditional home delivery has been decreased and hospital delivery has been increased remarkably within the decade.

\section{Changes in Modern Care Practice}

There was change noted within modern care practice. Practice of hospital delivery was increasing. During first delivery $70.67 \%$ had home delivery and $29.33 \%$ had hospital delivery during first delivery $(n=375)$. It was transformed to when their last delivery as $30.67 \%$ home delivery and $69.33 \%$ hospital delivery. Therefore trend of hospital delivery was increasing whereas trend of home delivery was decreasing. That was statistically highly significant $(\mathrm{p}=<0.0001)$. It was because of the government's policy and program being conducted in the name of safe motherhood. In the program government of Nepal has managed incentives for both mothers and health workers. Woman gets Rs 500 from government for transportation. Health workers and hospitals also received incentives for delivery. These are claimed by government on their annual reports.(14) Mothers' behavior has been socially constructed to have hospital delivery for safer child births.

There was also change in use of service providers in between first and last delivery. Use of doctors or skill birth attendants was increasing and demand of hospital environment with skilled health workers has been socially constructed. Among 375 mothers, use of TBAs was $8 \%$ at first delivery and only $1.87 \%$ used at last delivery. Similarly, use of Health workers at community was $6.67 \%$ at first delivery and $1.33 \%$ at last delivery. Use of TBA/CHW was $67.73 \%$ at first delivery that decreased to $27.2 \%$ at last delivery. Using HW/Nurse was 11.47 at first delivery also decreased to $3.2 \%$ at last delivery. But, there was remarkable increase in using Doctors/Nurse/HW at hospitals which was $6.13 \%$ at first delivery and was increased to $66.4 \%$ at last delivery. Therefore there was changes in use of skilled service providers that was statistically highly significant $(\mathrm{p}=$ $<.0001)$.

Traditional healers are a part of health care system in Rajbanshi community. They know their limitations and so they do refer to health 
institutions. Since traditional healers have got trainings from health posts they are aware of modern medications. They treat a case and hold normally for 1-2 days and if there is no sign of progress resulted be refered. Usually they are doing refered people to clinics or hospitals due to social construction of their behavior change. Rajbanshi communities are habited geographically on plain areas so that they have easy access of transportation to get health institutions. Due to efforts of government's public health programs focused especially on mother and child and availability of health workers and volunteers were more attracted with modern health system.

\section{Conclusion}

People were adopting both traditional and modern care practices concurrently. Among 375 households; 40\% adopted local clinic/ hospital/ traditional healer concurrently. Similarly $31.20 \%$ adopted local clinic/ traditional healer/ hospital, $10.67 \%$ adopted hospital/traditional healer, $9.6 \%$ adopted traditional healer/ local clinic/ hospital, 3.47\% adopted hospital practice, $2.4 \%$ adopted local clinic/hospital, and $1.33 \%$ adopted traditional healer/hospital concurrently. There were $11.47 \%$ (urban $0.54 \%$ and rural $10.93 \%$ ) respondents were having traditional care system as a first choice. During first delivery $70.67 \%$ had home delivery and $29.33 \%$ had hospital delivery was transformed to $30.67 \%$ home delivery and $69.33 \%$ hospital delivery during last delivery. Therefore trend of hospital delivery was increasing whereas trend of home delivery was decreasing. That was statistically highly significant $(\mathrm{p}=<0.0001)$. There was also remarkable increased in using trained $\mathrm{HW} / \mathrm{Nurse} / \mathrm{Doctor}$ at hospitals is $66.4 \%$ at last delivery which was only $6.13 \%$ at first delivery. It is statistically highly significant $(p=<.0001)$.

\section{References}

1. Chaudhary A.C. Koch Rajbonshi jono gosthir itihasaru sanskriti. Unic printers; 1969.

2. Ridge $\mathbf{O}$. A physical anthropological profile of the Koch of Darrang district, Assam; 1991

3. Shrestha I.G. Mohini-3 Rajbanshi. Published by Jamuna Shrestha, Biratnagar, Nepal; 2042

4. MMMS. Nepal Maternal Mortality and Morbidity Survey, 2008/2008, Ministry of Health, Department of Health Services, Family Health Division, Kathmandu, Nepal; (2008/09).

5. NDHS . Nepal Demographic and Health Survey 2011: Preliminary Report, Population Division, MoHP, Government of Nepal; 2011

6. Hitchcock J. Spirit Possession in the Nepal Himalayas. Warmister. Aris and Philips; 1976

7. Hawran D.Vergleichende Untersuchungen uber Krankheitsauffassungen und Krankheitsverhlaten in zwei nepalesischen Dofern. Freiburg: Unpublished Dissertation, cited from Boker, H. (1992) Concepts of Mental Illness: An Ethnographic Study, Contributions to Nepalese Studies. 1992;19 (1)

8. Subba N.R. Health Seeking Behavior of Rajbanshi Community in Katahari and Baijanathpur of Morang District, Nepal, Journal of Nepal Health Research Council. 2004;2 (1)

9. Subba S. Perception of disease and illness among health providers and health seekers in Jajarkot district, Nepal. The University of Copenhagen, 2003; P. 262

10. Saroha A. Altarac M. Caste and Maternal Health Care Service Use Among Rural Hindu Women in Maitha, Uttar Pradesh, India, Journal of Midwifery and Women's Health, Volume 53, Issue 5, September-October 2008; 41-47,

11.DeClue, J. A Journal of Midwifery and Women's Health, Bulletin of the American College of NurseMidwifery. 2004; 6( 4) :16-20

12.Kim, U. Berry J.WIndigenous Psychologies: Research and Experience in cultural Context, SAGE Publication, New Delhi; (1993). Moghaddam, F.M. Traditional and Modern Psychologies in competing cultural Systems: Lessons from Iran 1978-1981, Indigenous Psychologies: Research and Experience in cultural context, SAGE Publication, New Delhi; (1986). p118-131.

13. DoHS. Annual Report of FY 2067/68, Department of Health Services, Teku, Kathmandu, Nepal; $2069 / 70$

Corresponding author: Mr.Nawaraj Subba, MPH District Public Health Office, Morang, Nepal nrsubba@yahoo.com 